\title{
Variabilidade espacial de atributos do solo em sistema de semeadura direta com rotação de culturas no cerrado brasileiro ${ }^{1}$
}

\author{
Spatial variability of soil attributes in no a no-tillage system with crop rotation in the \\ brazilian savannah
}

\author{
Eduardo Leonel Bottega ${ }^{2 *}$, Daniel Marçal de Queiroz ${ }^{3}$, Francisco de Assis de Carvalho Pinto e Cristiano Márcio \\ Alves de Souza ${ }^{4}$
}

\begin{abstract}
RESUMO - O presente estudo objetivou analisar a variabilidade espacial dos atributos químicos e da textura de um Latossolo Vermelho distroférrico. A propriedade onde o estudo foi realizado localiza-se no município de Sidrolândia (MS) e produz soja, milho e algodão, adotando rotação de culturas e o sistema de plantio direto. Em uma área experimental de aproximadamente 90 hectares foi amostrado solo em 181 pontos georeferenciados. As amostras foram compostas por quatro amostras simples, representativas da profundidade de 0,00-0,20 m. Foram mensurados os atributos químicos e a textura do solo. Realizou-se, inicialmente, análise de discrepantes e, posteriormente, análise descritiva e geoestatística para caracterizar as amostras e identificar a dependência espacial dos atributos estudados. Não foi detectada dependência espacial para os atributos acidez ativa em água, alumínio, acidez potencial, saturação por bases e matéria orgânica. As melhores estimativas de valores para locais não amostrados foram observadas para os atributos físicos do solo, os quais apresentaram os melhores parâmetros de ajuste dos variogramas e da validação cruzada. As técnicas de geoestatística utilizadas possibilitaram o ajuste dos modelos teóricos que melhor representaram a semivariância experimental, possibilitando assim a construção de mapas temáticos da distribuição espacial dos valores dos atributos do solo estudado.
\end{abstract}

Palavras-chave: Latossolos. Agricultura de precisão. Semeadura.

\begin{abstract}
This study aimed to analyze the spatial variability of the chemical attributes and texture of a red latosol. The study was carried out on a property in the town of Sidrolândia, Matto Grosso do Sul, which produces soybeans, corn and cotton, using crop rotation and a no-tillage system. In an experimental area of approximately 90 hectares, samples were taken of the soil at 181 geo-referenced points. The samples were each composed of four single samples, representing depths of from 0 to $0.2 \mathrm{~m}$. The chemical and texture of the soil were measured. Initially a discrepancy analysis was performed followed by descriptive and geostatistical analyses, to characterize the samples and identify the spatial dependence of the attributes studied. No spatial dependence was detected for the attributes: active water acidity, aluminum, potential acidity, base saturation and organic matter. The best estimates of values for non-sampled locations were observed for the physical properties of the soil, which presented parameters which best fit the variograms and cross-validation. The geostatistical techniques used allowed adjustment of the theoretical models that best represented the experimental semivariance, thus enabling the construction of thematic maps of spatial distribution for the values of the attributes of the studied soil.
\end{abstract}

Key words: Oxisol. Precision agriculture. No-tillage.

\footnotetext{
*Autor para correspondência

${ }^{1}$ Recebido para publicação em 01/08/2011; aprovado em 03/06/2012

Parte da Dissertação do primeiro autor, bolsista de doutorado do CNPq

${ }^{2}$ Programa de Pós-Graduação em Engenharia Agrícola, Departamento de Engenharia Agrícola, Universidade Federal de Viçosa/UFV, Viçosa-MG, Brasil, eduardo-bottega@ hotmail.com

${ }^{3}$ Departamento de Engenharia Agrícola, Universidade Federal de Viçosa/UFV, Viçosa-MG, Brasil, dmqueiroz@gmail.com, facpinto@ufv.br

${ }^{4}$ Faculdade de Ciências Agrárias/FCA, Universidade Federal da Grande Dourados/UFGD, Dourados-MS, Brasil, csouza@ufgd.edu.br
} 


\section{INTRODUÇÃO}

O emprego de técnicas de agricultura de precisão, como sua utilização no manejo localizado da fertilidade do solo, vem sendo amplamente utilizado. As dosagens de insumos são aplicadas de forma variável, visando atender às necessidades específicas de cada local, otimizando o processo de produção e reduzindo os impactos ambientais causados pelas práticas agrícolas. Para tanto, é indispensável a caracterização da variabilidade espacial dos atributos químicos e físicos do solo por meio de amostragem capaz de representar tais variações.

A variabilidade espacial dos atributos dos solos é resultadode processos pedogenéticose pode ser demonstrada por resultados dos levantamentos e análises dos solos, bem como pelas diferenças encontradas nas produções das plantas (SILVA et al., 2010). Segundo Silva e Chaves (2001), com exceção do $\mathrm{pH}$ dos solos, os atributos químicos apresentam maior variação que os atributos físicos.

A caracterização da variabilidade espacial de atributos do solo no campo pode ser realizada por meio de amostragem e análise de solo, o que exige muito tempo e apresenta custo elevado. Corrêa, Tavares e Unibe-Opazo (2009) destacam que até recentemente, pesquisadores da área agronômica estudavam a variabilidade dos atributos do solo por meio da estatística clássica, a qual pressupõe que as observações de um dado atributo são independentes entre si, desconsiderando sua localização na área. Neste caso, os experimentos foram conduzidos para minimizar o impacto da variabilidade espacial, sendo ignorado o fato de que as observações podem ser espacialmente dependentes.

A geoestatística tem-se mostrado de grande utilidade na ciência do solo para caracterizar e estudar a variação espacial de suas propriedades. Assim, ao se estudar a fertilidade de um solo, há de se fazer um levantamento completo da mesma e caracterizar sua variabilidade espacial. Neste contexto, a utilização de variogramas e métodos de interpolação, como a krigagem, definem o grau de dependência no espaço de uma grandeza medida e o domínio de cada amostragem (MANZIONE; RODRIGUES; ZIMBACK, 2002).

O Cerrado ocupa quase toda área do Brasil central, com aproximadamente 200 milhões de hectares, em sua maior parte, na região Centro-Oeste. A maioria dos solos sob vegetação de cerrado tem sido diagnosticada como de baixa fertilidade natural, apresentando interferência direta na disponibilidade de nutrientes para as plantas se desenvolverem e atingirem altas produtividades. A baixa fertilidade dos solos pode ser corrigida, não constituindo um obstáculo para o cultivo da soja nas áreas agrícolas no bioma Cerrado (KLINK; MACHADO, 2005).

O sistema plantio direto (SPD) é uma das mais eficientes estratégias para a melhoria da qualidade e do potencial produtivo do solo agrícola (AMADO et al., 2007), pois representa a mais significativa alteração no manejo de solos da história moderna da agricultura. Este sistema envolve o uso de técnicas para produzir preservando a qualidade ambiental, fundamentando-se na ausência de preparo do solo e na presença de cobertura permanente sobre o terreno, por meio da rotação de culturas (MACHADO et al., 2004). O principal efeito da adoção do SPD em relação à variabilidade espacial pode ser observado para os atributos químicos do solo, uma vez que neste sistema não há preparo do solo (aração e gradagem).

Com base no exposto, objetivou-se com este estudo, analisar a variabilidade espacial dos atributos químicos e físicos do solo, por meio da elaboração de mapas temáticos, em uma área de produção agrícola cultivada no sistema de plantio direto com rotação de culturas.

\section{MATERIAL E MÉTODOS}

A coleta de dados foi realizada em uma fazenda localizada no município de Sidrolândia, Mato Grosso do Sul, zona UTM 21 Sul, com coordenadas 702879,040 m Leste e 7673084,461 m Norte, no datum SIRGAS 2000. A altitude média é de 490 metros. O relevo é considerado levemente ondulado. O solo predominante é classificado como Latossolo Vermelho distroférrico (EMPRESA BRASILEIRA DE PESQUISA AGROPECUÁRIA, 2006). Na fazenda cultiva-se soja (Glycine max), milho (Zea mays) e algodão (Gossypium hirsutum L.), adotando a rotação de culturas e o sistema de plantio direto. $\mathrm{O}$ trabalho foi conduzido em uma área de aproximadamente 90 hectares.

Para o mapeamento dos atributos físicos e químicos do solo foi utilizada uma grade com densidade de dois pontos por hectare, totalizando 181 pontos amostrais, conforme apresentado na Figura 1.

Os pontos amostrais foram georeferenciados utilizando-se um aparelho receptor GPS Topográfico de precisão centimétrica, com correção diferencial pósprocessada. Para correção diferencial foram utilizados os dados da base da Rede Brasileira de Monitoramento Contínuo (RBMC) do Instituto Brasileiro de Geografia e Estatística (IBGE), localizada no município de Campo Grande-MS. A correção foi realizada utilizando o programa computacional GNSS Solutions $^{\circledast}$ fornecido pelo fabricante do receptor GPS.

Em cada ponto georeferenciado, foi obtida uma amostra de solo composta por quatro amostras simples, representativas da camada de $0,00-0,20 \mathrm{~m}$ de profundidade. As amostras simples foram coletadas com trado holandês em um raio de 3,0 $\mathrm{m}$ do ponto georeferenciado e, após homogeneização, retirou-se aproximadamente $300 \mathrm{~g}$ de solo que foram colocados em embalagem plástica identificada. 
Figura 1 - Grade amostral utilizada na coleta de solo

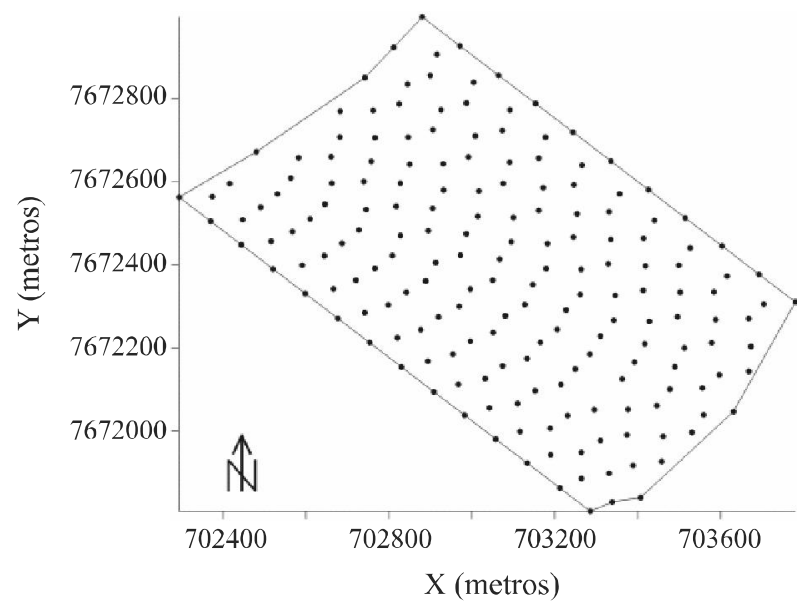

$\mathrm{O}$ atributo físico avaliado foi a textura e, na análise da composição textural, foram mensuradas as frações areia grossa, areia fina, silte e argila. Para caracterização química do solo, foram mensurados os valores de acidez ativa em água $(\mathrm{pH})$, acidez potencial $(\mathrm{H}+\mathrm{Al})$, cálcio $\left(\mathrm{Ca}^{2+}\right)$, magnésio $\left(\mathrm{Mg}^{2+}\right)$, potássio $\left(\mathrm{K}^{+}\right)$, alumínio $\left(\mathrm{Al}^{+3}\right)$, fósforo $(\mathrm{P})$, fósforo remanescente $(\mathrm{P}$ rem), matéria orgânica (MO), soma de bases (SB), capacidade de troca de cátions total ( $\mathrm{T}$ ) e a saturação por bases (V\%). Para mensuração do pH utilizou-se água na relação solo/solução $1: 2,5$. Os atributos químicos $\mathrm{P}$ e $\mathrm{K}^{+}$foram mensurados utilizando extrator Mehlich 1. Os valores de $\mathrm{Ca}^{2+}, \mathrm{Mg}^{2+}$ e $\mathrm{Al}^{3+}$ foram obtidos por

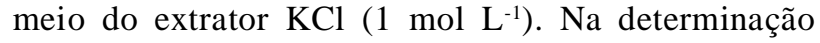
da MO utilizou-se o método de Walkley-Black (C orgânico x 1,724). Utilizando uma solução de $\mathrm{CaCl}_{2}(10$ mmol L $\mathrm{L}^{-1}$ ), contendo $60 \mathrm{mg} \mathrm{\textrm {L } ^ { - 1 }}$ de $\mathrm{P}$, foi determinado o P-rem. A acidez potencial foi determinada utilizando extrator Acetato de Cálcio $\left(0,5 \mathrm{~mol} \mathrm{~L}^{-1} \mathrm{pH} 7\right)$. Os valores de T, SB e V\% foram calculados utilizando equações clássicas (EMPRESA BRASILEIRA DE PESQUISA AGROPECUÁRIA, 1997).

Os valores dos atributos físicos e químicos do solo primeiramente foram submetidos à análise exploratória para verificar a presença de valores discrepantes e sua influência sobre as medidas de posição e dispersão. Nesta análise, o limite crítico para valores discrepantes é definido a partir da amplitude interquartil (DQ) calculada pela diferença entre o quartil superior e o quartil inferior. $\mathrm{O}$ limite superior foi definido por (Q3 + 1,5 x DQ) e o limite inferior por (Q1 - 1,5 x DQ), em que Q1 e Q3 constituem o primeiro e o terceiro quartil, respectivamente. Depois de identificados, realizou-se análise visual da localização espacial destes valores dentro da grade amostral, para auxiliar na tomada de decisão de eliminação ou não destes discrepantes. Em seguida, os dados foram analisados por meio de estatística descritiva, calculando-se a média, mediana, valor mínimo, valor máximo, desvio padrão, coeficiente de variação, quartil inferior e quartil superior, buscando assim caracterizá-los.

A dependência espacial foi avaliada pelos ajustes de variogramas, pressupondo a estacionariedade da hipótese intrínseca, definida pela equação 1 .

$$
\hat{\gamma}(h)=\frac{1}{2 N(h)} \sum_{i=1}^{N(h)}[Z(x i)-Z(x i+h)]^{2}
$$

Em que: $\hat{y}(h)=$ semivariância em função da distância de separação $(h)$ entre pares de pontos; $h=$ distância de separação entre pares de pontos, $\mathrm{m} ; N(h)=$ número de pares pontos experimentais separados por uma distância $h$.

O variograma é representado pelo gráfico $\gamma(h)$ versus $h$. Foram testados os modelos gaussiano, esférico e exponencial. Ajustou-se o modelo que melhor representou a relação entre semivariância experimental e a distância $h$, e determinou-se os parâmetros: efeito pepita $\left(C_{0}\right)$, patamar $\left(C_{0}+C\right)$ e alcance $(\mathrm{A})$.

Uma vez detectada a dependência espacial, produziu-se o mapa temático da distribuição espacial do atributo por meio de krigagem ordinária. Para interpolação utilizou-se 16 vizinhos próximos, em um raio de busca equivalente ao alcance do variograma. Grego e Vieira (2005) ressaltam que as construções de mapas com os valores obtidos por meio de krigagem são importantes para a verificação e interpretação da variabilidade espacial. A análise geoestatística dos dados é completada com as informações mostradas nos mapas, que são úteis nas tomadas de decisões.

O índice de dependência espacial dos atributos (IDE) foi determinado e classificado segundo Zimback (2001), utilizando a equação 2 e assumindo os seguintes intervalos: dependência espacial baixa para IDE $\leq 25 \%$, moderada para $25 \% \leq \mathrm{IDE} \leq 75 \%$ e forte para IDE $>75 \%$.

$$
I D E=\left(\frac{C}{C_{0}+C}\right) \times 100
$$

Onde: IDE = índice de dependência espacial; $C=$ contribuição da semivariância $\left(C_{0}+C-C_{0}\right) ; C_{0}+C=$ patamar.

A análise estatística foi realizada no programa Statistica, versão 7. A análise geoestatística e os modelos dos semivariogramas dos atributos estudados foram ajustados utilizando o programa de computador GS+, versão 9. Os mapas temáticos foram gerados utilizando o programa Surfer, versão 8.0. 


\section{RESULTADOS E DISCUSSÃO}

Todos os atributos analisados apresentaram valores discrepantes, sendo o máximo de seis valores para os atributos areia grossa e alumínio e o mínimo de dois valores para os atributos areia fina, capacidade de troca de cátions total, matéria orgânica e fósforo remanescente. Estes valores influenciaram as medidas de dispersão e posição, sendo assim removidos da base de dados utilizada para análises subsequentes. Hoaglin, Masteller e Tykey (1983) afirmam que valores discrepantes, na maioria dos casos, alteram os valores de medidas sensíveis a estas observações, como a média, amplitude, o desvio-padrão e a assimetria da distribuição dos dados. Libardi et al. (1996) destacam que o procedimento de retirada dos valores discrepantes favorece a obtenção de um resumo estatístico mais confiável, capaz de melhor representar a variabilidade dos dados, principalmente no que diz respeito às medidas de tendência central.

$\mathrm{Na}$ Tabela 1 são apresentados os valores de estatística descritiva dos atributos do solo. Observou-se que os coeficientes de variação (CV\%) variaram de 3,70 a $134,98 \%$. De acordo com a classificação proposta por Warrick e Nielsen (1980), os valores de CV para argila, acidez ativa em água, capacidade de troca de cátions total e matéria orgânica são classificados como baixos $(\mathrm{CV}<12 \%)$. Como valores altos $(\mathrm{CV}>60 \%)$ foram classificados os atributos: fósforo e alumínio. Os demais atributos apresentaram valores de CV classificados como coeficiente de média variação $(12 \%<\mathrm{CV}<60 \%)$. Valores elevados de $\mathrm{CV}$ podem ser considerados como os primeiros indicadores da existência de heterogeneidade nos dados (FROGBROOK et al., 2002). Segundo Silva e Chaves (2001), as variações dos atributos químicos do solo estão relacionadas a alterações provocadas pelas adubações e calagens sucessivas e irregulares.

Os valores médios dos atributos químicos do solo foram classificados, segundo Empresa Brasileira de Pesquisa Agropecuária (2008) para a região central do Brasil, como elevados para cálcio, magnésio, fósforo, potássio, fósforo remanescente, acidez potencial e matéria orgânica. Foram classificados como médios os atributos soma de bases, capacidade de troca de cátions total, saturação por bases e acidez ativa em água. Os atributos alumínio e saturação por alumínio, segundo a classificação, são considerados baixos.

Os bons resultados observados, em especial para os valores médios dos teores de cálcio, magnésio, fósforo remanescente e potássio, podem ser explicados pelo sistema de manejo adotado na propriedade, plantio direto com rotação de culturas. Alguns pesquisadores (SILVEIRA; STONE, 2001; SOUZA; ALVES, 2003) enfatizam que o sistema plantio direto (SPD), quando associado

Tabela 1 - Estatística descritiva dos atributos do solo

\begin{tabular}{|c|c|c|c|c|c|c|c|c|}
\hline Atributos & Média & Mediana & Mín. & Máx. & $\mathrm{S}^{(8)}$ & $\mathrm{CV}^{(9)}(\%)$ & $\mathrm{QI}^{(10)}$ & $\mathrm{QS}^{(11)}$ \\
\hline Areia grossa* & 2,37 & 2,00 & 1,00 & 5,00 & 0,80 & 34,00 & 2,00 & 3,00 \\
\hline Areia fina* & 10,19 & 10,00 & 7,00 & 13,00 & 1,44 & 14,14 & 9,00 & 11,00 \\
\hline Silte* & 23,84 & 24,00 & 16,00 & 32,00 & 3,76 & 15,77 & 21,00 & 27,00 \\
\hline Argila* & 63,51 & 64,00 & 56,00 & 70,00 & 2,68 & 4,22 & 62,00 & 65,00 \\
\hline $\mathrm{pH}^{(1)}$ & 5,50 & 5,50 & 4,88 & 6,10 & 0,20 & 3,70 & 5,36 & 5,61 \\
\hline $\mathrm{P}\left(\mathrm{mg} \mathrm{dm} \mathrm{m}^{-3}\right)$ & 24,37 & 19,15 & 5,20 & 70,90 & 15,34 & 62,94 & 14,40 & 29,70 \\
\hline $\mathrm{K}\left(\mathrm{mg} \mathrm{dm}{ }^{-3}\right)$ & 200,55 & 194,00 & 71,00 & 354,00 & 54,60 & 27,22 & 168,00 & 220,00 \\
\hline $\mathrm{Ca}^{2+}\left(\mathrm{cmol}_{\mathrm{c}} \mathrm{dm}^{-3}\right)$ & 3,63 & 3,60 & 2,25 & 5,47 & 0,56 & 15,37 & 3,29 & 3,97 \\
\hline $\mathrm{Mg}^{2+}\left(\mathrm{cmol}_{\mathrm{c}} \mathrm{dm}^{-3}\right)$ & 0,92 & 0,91 & 0,48 & 1,43 & 0,20 & 22,00 & 0,77 & 1,07 \\
\hline $\mathrm{Al}^{3+}\left(\mathrm{cmol}_{\mathrm{c}} \mathrm{dm}^{-3}\right)$ & 0,05 & 0,00 & 0,00 & 0,30 & 0,07 & 134,98 & 0,00 & 0,10 \\
\hline $\mathrm{H}+\mathrm{Al}^{(2)}\left(\mathrm{cmol}_{\mathrm{c}} \mathrm{dm}^{-3}\right)$ & 6,13 & 6,00 & 3,80 & 8,50 & 0,91 & 14,83 & 5,50 & 6,70 \\
\hline $\mathrm{SB}^{(3)}\left(\mathrm{cmol}_{\mathrm{c}} \mathrm{dm}^{-3}\right)$ & 5,07 & 4,98 & 3,20 & 7,24 & 0,75 & 14,86 & 4,60 & 5,61 \\
\hline $\mathrm{T}^{(4)}\left(\mathrm{cmol}_{\mathrm{c}} \mathrm{dm}^{-3}\right)$ & 11,19 & 11,23 & 8,96 & 13,18 & 0,81 & 7,25 & 10,60 & 11,73 \\
\hline $\mathrm{V}^{(5)}(\%)$ & 45,33 & 45,40 & 28,10 & 65,00 & 6,45 & 14,24 & 41,30 & 49,20 \\
\hline $\mathrm{MO}^{*(6)}$ & 3,77 & 3,80 & 3,14 & 4,44 & 0,26 & 6,88 & 3,64 & 3,93 \\
\hline P-rem ${ }^{(7)}\left(\mathrm{mg} \mathrm{L}^{-1}\right)$ & 20,12 & 20,50 & 13,30 & 26,30 & 2,69 & 13,38 & 18,30 & 22,00 \\
\hline
\end{tabular}

*dag kg ${ }^{-1} ;{ }^{(1)}$ Acidez ativa em água; ${ }^{(2)}$ Acidez potencial; ${ }^{(3)}$ Soma de bases; ${ }^{(4)}$ Capacidade de troca de cátions total; ${ }^{(5)}$ Saturação por bases; ${ }^{(6)}$ Matéria orgânica; ${ }^{(7)}$ Fósforo remanescente; ${ }^{(8)}$ Desvio padrão; ${ }^{(9)}$ Coeficiente de variação; ${ }^{(10)}$ Quartil inferior; ${ }^{(11)}$ Quartil superior 
à rotação de culturas anuais, alteram as propriedades químicas do solo, com aumento dos teores de matéria orgânica, variações no $\mathrm{pH}$ do solo, na capacidade de troca catiônica, bem como nas bases trocáveis e no fósforo disponível, além da diminuição do alumínio trocável, melhorando as condições do solo. Ciotta et al. (2003) estudando os efeitos do acúmulo de matéria orgânica sobre a capacidade de troca de cátions de um solo com argila de baixa reatividade, concluíram que o acúmulo de matéria orgânica após 21 anos da adoção do SPD, em solo argiloso e com mineralogia oxídica, promoveu aumento expressivo na CTC do solo, fundamental para este cenário onde se tem predominância de minerais de baixa atividade na fração argila.

Na Tabela 2 são apresentados os parâmetros dos variogramas ajustados aos modelos teóricos que melhor descrevem o comportamento da variabilidade espacial dos atributos estudados. São apresentados os seguintes parâmetros: modelo; alcance (a); patamar $\left(\mathrm{C}_{0}+\mathrm{C}\right)$; efeito pepita $\left(\mathrm{C}_{0}\right)$; índice de dependência espacial (IDE), soma de quadrados do resíduo e coeficiente de determinação $\left(\mathrm{R}^{2}\right)$.

A menor distância entre pontos amostrais foi de 49,98 metros. Os atributos acidez ativa em água, alumínio, acidez potencial, saturação por bases e matéria orgânica não apresentaram dependência espacial. A falta de dependência é um indicativo de que o valor de semivariância é igual ao patamar, para qualquer valor de distância. A ausência total de dependência espacial é chamada efeito pepita puro. O efeito pepita puro indica que a distribuição espacial do atributo na área de estudo é homogênea, aleatória ou a malha amostral utilizada não possui pontos suficientes para detectar a dependência que, se existir, será manifestada à distâncias menores que o menor espaçamento entre amostras (GUIMARÃES, 2004). No presente estudo, a causa mais provável da homogeneidade espacial observada para os atributos químicos do solo: acidez ativa em água, alumínio, acidez potencial, saturação por bases e matéria orgânica, pode estar associada ao sistema de cultivo, plantio direto com rotações de culturas.

O maior coeficiente de determinação observado para o ajuste do modelo foi 0,99 na modelagem da dependência espacial da areia fina e o menor coeficiente foi 0,55 na modelagem da dependência espacial da soma de bases. Todos os modelos foram selecionados após análise de validação cruzada. O modelo teórico que apresentou melhor ajuste para a semivariância empírica do atributo físico do solo foi o gaussiano. O modelo gaussiano é representativo de fenômenos extremamente contínuos, indicando suave variação em pequenas distâncias de

Tabela 2 - Parâmetros dos modelos teóricos de semivariância ajustados para os atributos físicos e químicos do solo

\begin{tabular}{lccccccc}
\hline \multicolumn{1}{c}{ Atributos } & Modelo & Alcance $(\mathrm{m})$ & $\mathrm{C} 0+\mathrm{C}^{(8)}$ & $\mathrm{C}^{(9)}$ & $\mathrm{IDE}^{(10)}$ & $\mathrm{SQR}^{(11)}$ & $\mathrm{R}^{2(12)}$ \\
\hline Areia grossa $\left(\mathrm{dag} \mathrm{kg}^{-1}\right)$ & Gaussiano & 490 & 0,76 & 0,37 & 51 & 0,01 & 0,96 \\
Areia fina $\left(\mathrm{dag} \mathrm{kg}^{-1}\right)$ & Gaussiano & 748 & 4,16 & 0,66 & 84 & 0,09 & 0,99 \\
Silte $\left(\mathrm{dag} \mathrm{kg}^{-1}\right)$ & Gaussiano & 858 & 31,04 & 5,21 & 83 & 19 & 0,96 \\
Argila $\left.(\mathrm{dag} \mathrm{kg})^{-1}\right)$ & Gaussiano & 910 & 13,01 & 4,77 & 63 & 5,04 & 0,95 \\
$\mathrm{pH}^{(1)}$ & EPP* & - & - & - & - & - & - \\
$\mathrm{P}\left(\mathrm{mg} \mathrm{dm}^{-3}\right)$ & Exponencial & 178 & 241,10 & 120,50 & 50 & 812 & 0,91 \\
$\mathrm{~K}\left(\mathrm{mg} \mathrm{dm}^{-3}\right)$ & Esférico & 205 & 2353 & 1176 & 50 & 138515 & 0,62 \\
$\mathrm{Ca}^{2+}\left(\mathrm{cmol}_{\mathrm{c}} \mathrm{dm}^{-3}\right)$ & Esférico & 116 & 0,21 & 0,09 & 57 & 0,00 & 0,61 \\
$\mathrm{Mg}^{2+}\left(\mathrm{cmol}_{\mathrm{c}} \mathrm{dm}^{-3}\right)$ & Esférico & 1349 & 0,05 & 0,03 & 51 & 0,00 & 0,96 \\
$\mathrm{Al}^{+3}\left(\mathrm{cmol}_{\mathrm{c}} \mathrm{dm}^{-3}\right)$ & EPP & - & - & - & - & - & - \\
$\mathrm{H}_{+} \mathrm{Al}^{(2)}\left(\mathrm{cmol}_{\mathrm{c}} \mathrm{dm}^{-3}\right)$ & EPP & - & - & - & - & - & - \\
$\mathrm{SB}^{(3)}\left(\mathrm{cmol}_{\mathrm{c}} \mathrm{dm}^{-3}\right)$ & Exponencial & 125 & 0,46 & 0,24 & 48 & 0,01 & 0,55 \\
$\mathrm{~T}^{(4)}\left(\mathrm{cmol}_{\mathrm{c}} \mathrm{dm}^{-3}\right)$ & Exponencial & 108 & 0,50 & 0,21 & 58 & 0,01 & 0,78 \\
$\mathrm{~V}^{(5)}(\%)$ & EPP & - & - & - & - & - & - \\
$\mathrm{MO}^{(6)}\left(\mathrm{dag} \mathrm{kg}^{-1}\right)$ & EPP & - & - & - & - & - & - \\
$\mathrm{P}-\mathrm{rem}^{(7)}\left(\mathrm{mg} \mathrm{L}^{-1}\right)$ & Gaussiano & 1125 & 11,53 & 5,76 & 50 & 10,70 \\
\hline
\end{tabular}

(1) Acidez ativa em água; ${ }^{(2)}$ Acidez potencial; ${ }^{(3)}$ Soma de bases; ${ }^{(4)}$ Capacidade de troca de cátions total; ${ }^{(5)}$ Saturação por bases; ${ }^{(6)}$ Matéria orgânica; ${ }^{(7)}$ Fósforo remanescente; ${ }^{(8)}$ Patamar; ${ }^{(9)}$ Efeito pepita ${ }^{(10)}$ Índice de dependência espacial; ${ }^{(11)}$ Soma de quadrados do resíduo; ${ }^{(12)}$ Coeficiente de determinação; *Efeito pepita puro 
observação. O maior alcance foi observado para argila $(910 \mathrm{~m})$, isso demonstra que este atributo, dentre os atributos que compõem a textura do solo, é o que apresenta menor variabilidade e maior continuidade espacial, garantindo melhor precisão nas estimativas em locais não amostrados. Uma das possíveis causas desta continuidade pode estar associada ao material de origem do solo e ação do processo de intemperismo, sendo o relevo levemente ondulado e o sistema adotado é o SPD a ação resultante do transporte de sedimentos (neste caso principalmente pelo vento) é irrelevante, porém, apenas com estudo mais detalhado é possível se confirmar esta hipótese.

$\mathrm{O}$ modelo teórico que melhor se ajustou à semivariância empírica dos dados, em função da distância, para os atributos químicos potássio, cálcio e magnésio, foi o exponencial. Cavalcante et al. (2007) e Souza et al. (2004b), estudando a variabilidade espacial de atributos químicos, obtiveram resultados semelhantes. Para a semivariância experimental dos atributos químicos fósforo, soma de bases e capacidade de troca de cátions total o modelo teórico exponencial foi o que apresentou melhor ajuste. O modelo teórico gaussiano foi o que apresentou melhor ajuste à semivariância empírica do atributo fósforo remanescente.

A continuidade da variabilidade espacial dos atributos químicos é menor que a continuidade da variabilidade espacial da textura do solo. O modelo exponencial e o modelo esférico representam, respectivamente, média e baixa continuidade da variabilidade espacial; já o modelo gaussiano, representa elevada continuidade da variabilidade espacial. Estes ajustes podem ser explicados pela maior facilidade de alteração que o homem pode promover no solo, que está relacionada aos atributos químicos e aos atributos físicos associados à estrutura (grau de compactação, porosidade, agregação, etc.), que variam em função do tipo de preparo do solo, tipo de cultivo e, principalmente, das práticas de fertilização (SILVA; CHAVES, 2001). Já a textura (areia, silte, argila) é um atributo físico dependente do material de origem. Modificações na textura do solo podem levar vários anos para acontecer e são reflexos do processo de intemperismo, sendo mais facilmente visualizadas em áreas de relevo acidentado. A utilização do solo para cultivo de grãos tem pouco efeito sobre a textura, especialmente na condição da área de estudos, onde o relevo é considerado levemente ondulado e sistema de cultivo adotado é o SPD, porém, a adoção deste sistema pode levar a mudanças estruturais do solo, modificando principalmente a agregação e a porosidade.

O maior alcance $(1.349 \mathrm{~m})$ e o menor alcance $(108 \mathrm{~m})$ foram observados, respectivamente, para magnésio e para a capacidade de troca de cátions total. Como informado anteriormente, a distância mínima entre os pontos amostrais foi de 49,98 metros; considerando que a metade do menor alcance observado é de 54 metros, o presente estudo está em acordo com estudos realizados por Carvalho, Silveira e Vieira (2002), nos quais os autores demonstram que, ao se considerar como distância entre pontos amostrais a metade do valor do alcance, é garantida a detecção da variabilidade espacial do atributo em estudo sem perder precisão nas estimativas, pois a continuidade espacial do atributo é mantida.

Os valores de alcance podem influenciar na qualidade das estimativas, uma vez que ele determina o número de valores usados na interpolação. Assim, estimativas feitas com interpolação por krigagem ordinária utilizando valores de alcances maiores tendem a ser mais confiáveis, apresentando mapas que representem melhor a realidade (CORÁ et al., 2004). Zanão Júnior, Lana e Guimarães (2007) destacam que a variabilidade espacial dos nutrientes pode não ser igual entre eles. Alguns nutrientes necessitam de números maiores de amostras que outros para que se possa conhecer sua disponibilidade em relação a uma determinada área. Isso acontece porque as variações nos teores dos elementos do solo não são uniformes para todos.

Foi constatada forte dependência espacial para as quantidades de areia fina e silte (IDE de 84 e 83) e moderada dependência espacial para areia grossa e argila (IDE de 51 e 63). Todos os atributos químicos do solo apresentaram dependência espacial classificada como moderada, de acordo com classificação proposta por Zimback (2001). Para o ajuste dos modelos teóricos de semivariância da textura do solo, os valores do coeficiente de determinação observados foram acima de 0,95 . Na modelagem da dependência espacial dos atributos químicos, o menor coeficiente de determinação observado foi 0,55 para soma de bases e o maior foi 0,91 para fósforo. Vale lembrar que somente este valor não é indicativo de que o ajuste obtido é o que melhor representa a variabilidade espacial do atributo em estudo. Este coeficiente pode ser utilizado como parâmetro na decisão de qual modelo melhor se ajustou a semivariância experimental.

São apresentados na Tabela 3 os parâmetros da validação cruzada dos modelos teóricos de semivariância ajustados para os atributos do solo da área amostrada. Os parâmetros apresentados são: coeficiente de regressão; intercepto; erro padrão e coeficiente de determinação.

Os menores coeficientes de determinação para a estimativa da textura do solo em locais não amostrados 
Tabela 3 - Parâmetros da validação cruzada dos modelos teóricos de semivariância ajustados para os atributos químicos e físicos do solo

\begin{tabular}{lcccc}
\hline \multicolumn{1}{c}{ Atributos } & Coeficiente de regressão & Intercepto (Y) & Erro padrão (SE) & $\mathrm{R}^{\mathbf{2}^{(4)}}$ \\
\hline Areia grossa $(\mathrm{dag} \mathrm{kg})$ & 1,09 & $-0,2$ & 0,096 & 0,43 \\
Areia fina $\left.(\mathrm{dag} \mathrm{kg})^{-1}\right)$ & 1,01 & $-0,11$ & 0,056 & 0,65 \\
Silte $(\mathrm{dag} \mathrm{kg})^{-1}$ & 1,02 & $-0,39$ & 0,061 & 0,61 \\
Argila $\left(\mathrm{dag} \mathrm{kg}^{-1}\right)$ & 0,98 & 0,36 & 0,114 & 0,30 \\
$\mathrm{P}\left(\mathrm{mg} \mathrm{dm}^{-3}\right)$ & 0,85 & 3,36 & 0,138 & 0,19 \\
$\mathrm{~K}\left(\mathrm{mg} \mathrm{dm}^{-3}\right)$ & 0,70 & 58,57 & 0,151 & 0,12 \\
$\mathrm{Ca}^{2+}\left(\mathrm{cmol}_{\mathrm{c}} \mathrm{dm}^{-3}\right)$ & 0,69 & 1,13 & 0,157 & 0,11 \\
$\mathrm{Mg}^{2+}\left(\mathrm{cmol}_{\mathrm{c}} \mathrm{dm}^{-3}\right)$ & 0,84 & 0,15 & 0,145 & 0,16 \\
$\mathrm{SB}^{(1)}\left(\mathrm{cmol}_{\mathrm{c}} \mathrm{dm}^{-3}\right)$ & 0,76 & 0,158 & 0,12 \\
$\mathrm{~T}^{(2)}\left(\mathrm{cmol}_{\mathrm{c}} \mathrm{dm}^{-3}\right)$ & 0,79 & 2,37 & 0,103 & 0,26 \\
$\mathrm{P}_{-} \mathrm{rem}^{(3)}\left(\mathrm{mg} \mathrm{L}^{-1}\right)$ & 0,90 & 1,99 & 0,135 & 0,20 \\
\hline
\end{tabular}

${ }^{(1)}$ Soma de bases; ${ }^{(2)}$ Capacidade de troca cátions total; ${ }^{(3)}$ Fósforo remanescente; ${ }^{(4)}$ Coeficiente de determinação

foram observados para os teores de argila $(0,30)$ e areia grossa $(0,43)$. As mesmas frações apresentaram valores do coeficiente de regressão mais distantes de 1 , sendo 1,09 e 0,98 , respectivamente. As frações areia fina e silte apresentaram valores próximos ao ideal (coeficiente de regressão e de determinação igual a 1), tanto para o coeficiente de regressão $(1,01$ e 1,02$)$ quanto para o coeficiente de determinação $(0,65$ e 0,61$)$. Todos os atributos apresentaram erro padrão bem próximo a zero, o que, associado aos demais parâmetros, demonstra que o modelo ajustado teve uma boa precisão na estimativa de valores destes atributos em locais não amostrados.

Analisando os atributos químicos do solo, uma pequena diferença entre os valores do coeficiente de determinação foi observada. $\mathrm{O}$ menor valor encontrado foi de 0,11 para cálcio e o maior valor 0,26 foi observado para capacidade de troca de cátions total. O maior coeficiente de regressão foi observado para a validação cruzada do atributo fósforo remanescente $(0,90)$ e o menor para potássio $(0,70)$. O baixo coeficiente de regressão é decorrente da dispersão da nuvem de pontos em torno da reta ideal, que possui coeficiente angular de valor 1 e corta a origem do eixo y (intercepto) no valor zero.

A fração areia fina apresentou um dos menores valores de erro padrão, pois embora dispersa a nuvem de pontos, os mesmos mantém um padrão de dispersão uniforme, não sendo observada a presença de pontos discrepantes ao arranjo da nuvem. Assim como o atributo físico analisado, os atributos químicos do solo apresentaram valores de erro padrão bem próximos a zero, porém, um pouco maiores que os observados para a validação do atributo físico.
Baseado nos modelos de semivariância e levando-se em consideração os parâmetros ajustados para os atributos químicos e físicos do solo, utilizando a técnica de krigagem ordinária, foram interpolados os valores amostrados a fim de se construir os mapas da variabilidade espacial dos atributos estudados. Os mapas são apresentados na Figura 2 e foram confeccionados utilizando 5 classes de divisão, afim de buscar uma melhor representação da distribuição dos valores na área de estudo.

Os mapas das frações areia grossa e fina apresentam similaridade na localização dos maiores e menores valores destas frações; porém, em diferentes proporções de área. A geoespacialização de silte apresenta-se com distribuição contrária à distribuição dos valores de areia grossa e areia fina, ou seja, onde se observam maiores concentrações de areia, menores as concentrações de silte, e vice-versa. De acordo com Souza et al. (2004a), as frações do solo geralmente apresentam comportamento inverso, principalmente de distribuição, pois como são medidos em porcentagem quando há acréscimo de um ocorre redução de outro.

O mapa de distribuição espacial de fósforo remanescente pode servir como importante ferramenta para se conhecer a localização de áreas com maior e menor disponibilidade de fósforo (DONOGEMMA et al., 2008). Assim, ele pode ser utilizado, por exemplo, como alternativa para estimativas de recomendação de doses para aplicação de fertilizante fosfatado a taxas variadas. Pequenas manchas observadas nos mapas da distribuição espacial dos atributos químicos são reflexos da baixa precisão na estimativa de valores em regiões não amostradas, o mesmo pode ser confirmado 
Figura 2 - Mapas de distribuição espacial dos atributos do solo da área estudada

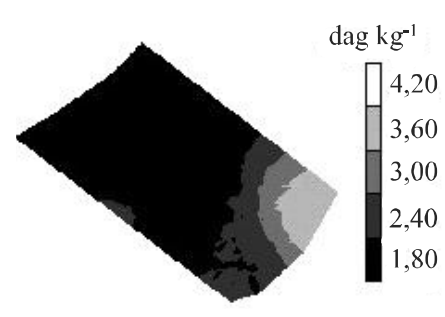

Areia grossa
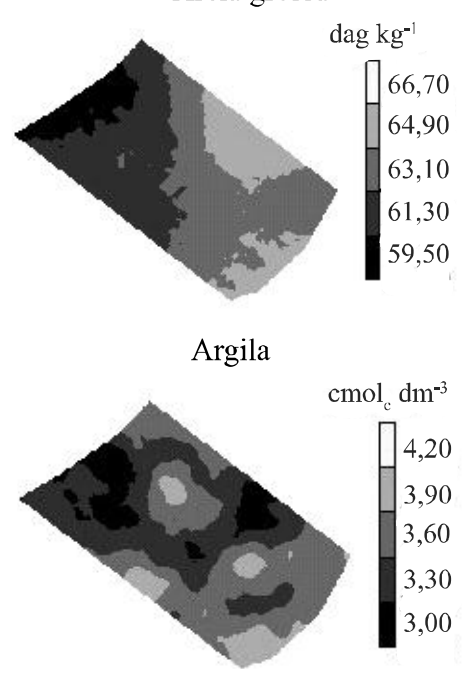

Cálcio $(\mathrm{Ca})$

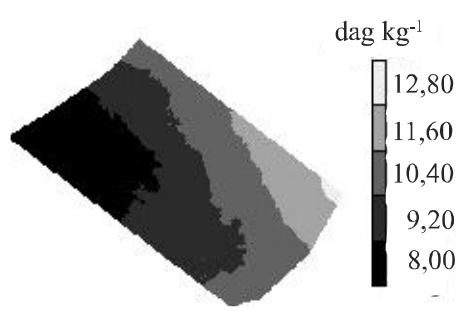

Areia fina

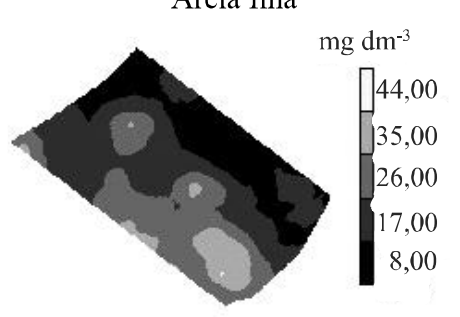

Fósforo (P)

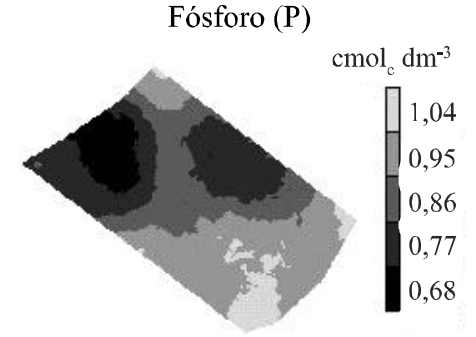

Magnésio $(\mathrm{Mg})$

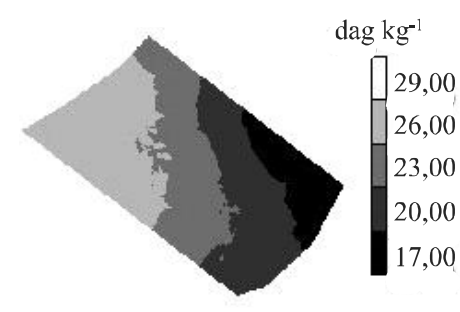

Silte

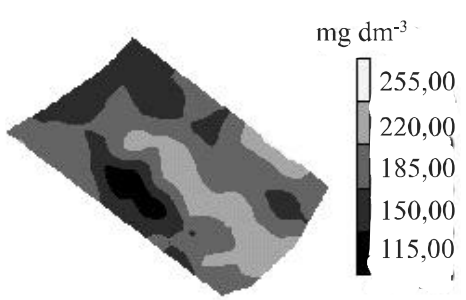

Potássio (K)

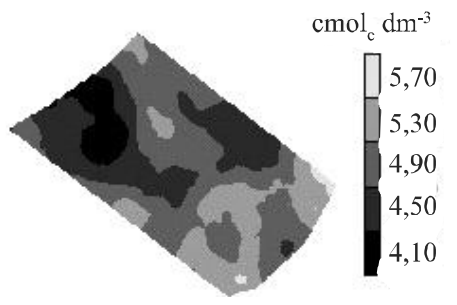

Soma de bases (SB)

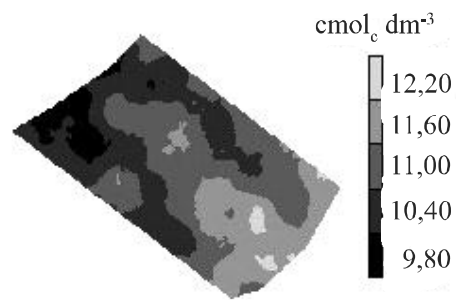

Capacidade de troca de cátions total (T)

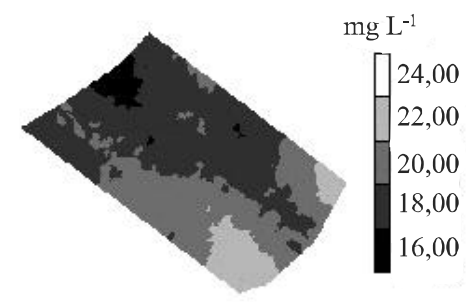

Fósforo remanescente (P -rem)

analisando os baixos valores dos parâmetros de ajuste da validação cruzada e dos modelos teóricos de semivariância. O contrário é observado para os mapas temáticos de distribuição espacial dos atributos físicos do solo, os quais apresentam maior continuidade da distribuição dos valores ao longo da área amostrada.

\section{CONCLUSÃO}

As melhores estimativas de valores para locais não amostrados foram observadas para a textura do solo, os quais apresentaram os melhores parâmetros de ajuste dos variogramas e da validação cruzada.

\section{AGRADECIMENTOS}

Ao Conselho Nacional de Desenvolvimento Científico e Tecnológico(CNPq) pela concessão de bolsa de estudo, a Fazenda Recanto pela disponibilização da área e apoio logístico para a realização deste estudo e a Fundação de Amparo à Pesquisa de Minas Gerais (FAPEMIG).

\section{REFERÊNCIAS}

AMADO, T. J. C. et al. Variabilidade espacial e temporal da produtividade de culturas sob sistema plantio direto. Pesquisa Agropecuária Brasileira, v. 42, n. 08, p. 1101-1110, 2007. 
CARVALHO, J. R. P. de; SILVEIRA, P. M. da; VIEIRA, S. R. Geoestatística na determinação da variabilidade espacial de características químicas do solo sob diferentes preparos. Pesquisa Agropecuária Brasileira, v. 37, n. 08, p. 1151-1159, 2002.

CAVALCANTE, E. G. S. et al. Variabilidade espacial de atributos químicos do solo sob diferentes usos e manejos. Revista Brasileira de Ciência do Solo, v. 31, p. 1329-1339, 2007.

CIOTTA, M. N. et al. Matéria orgânica e aumento da capacidade de troca de cátions em solo com argila de atividade baixa sob plantio direto. Ciência Rural, v. 33, n. 06, p. 1161-1164, 2003.

CORÁ, J. E. et al. Variabilidade espacial de atributos do solo para adoção do sistema de agricultura de precisão na cultura de cana-de-açúcar. Revista Brasileira de Ciência do Solo, v. 28, n. 06, p. 1013-1021, 2004.

CORRÊA, A. N.; TAVARES, M. H. F.; URIBE-OPAZO, M. A. Variabilidade espacial de atributos físicos do solo e seus efeitos sobre a produtividade do trigo. Semina: ciências agrárias, v. 30, n. 01, p. 81-94, 2009.

DONOGEMMA, G. K. et al. Fósforo remanescente em argila e silte retirados em Latossolos após pré-tratamentos na análise textural. Revista Brasileira de Ciência do Solo, v. 32, p. 1785-1791, 2008.

EMPRESA BRASILEIRA DE PESQUISA AGROPECUÁRIA. Centro Nacional de Pesquisa de Solos. Sistema Brasileiro de Classificação de Solos. Rio de Janeiro, 2006. 412 p.

EMPRESA BRASILEIRA DE PESQUISA AGROPECUÁRIA. Centro Nacional de Pesquisa de Solos. Manual de métodos de análise de solo. 2. ed. Rio de Janeiro: Ministério da Agricultura e do Abastecimento, 1997.212 p.

EMPRESA BRASILEIRA DE PESQUISA AGROPECUÁRIA. Tecnologias de produção de soja para região central do Brasil. Londrina, 2008. 262 p.

FROGBROOK, Z. L. et al. Exploring the spatial relations between cereal yield and soil chemical properties and the implications for sampling. Soil Use and Management, v. 18, n. 01, p. 01-09, 2002.

GREGO, C. R.; VIEIRA, S. R. Variabilidade espacial de propriedades físicas do solo em uma parcela experimental. Revista Brasileira de Ciência do Solo, v. 29, n. 02, p. 169-177, 2005.

GUIMARÃES, E. C. Geoestatística básica e aplicada. Uberlândia: Universidade Federal de Uberlândia. 2004. 76 p.

HOAGLIN, D. C.; MOSTELlER, F.; TYKEY, J. W. Análise exploratória de dados: técnicas robustas, um guia. Lisboa: Salamandra, 1983. 446 p.

KLINK, C. A.; MACHADO, R. B. A conservação do cerrado brasileiro. Revista Megadiversidade, v. 01, n. 01, p. 147155, 2005.
LIBARDI, P. L. et al. Variabilidade da umidade gravimétrica de um solo hidromórfico. Revista Brasileira de Ciência do Solo, v. 20, n. 01, p. 01-12, 1996.

MACHADO, P. L. O. de A. et al. Estudo de caso em agricultura de precisão: manejo de lavoura de soja na região de campos gerais, PR. In: MACHADO, P. L. O. de A.; BERNARDI, A. C. de C.; SILVA, C. A. (Ed.). Agricultura de precisão para o manejo da fertilidade do solo em sistema plantio direto. (Ed.). Rio de Janeiro: EMBRAPA Solos, 2004. p. 93-113.

MANZIONE, R. L.; RODRIGUES, J. B. T.; ZIMBACK, C. R. L. Análise espacial multivariada na avaliação de parâmetros químicos do solo. In: BALASTREIRE, L. A. Avanços na Agricultura de Precisão no Brasil no período de 1999-2001. Piracicaba, 2002. 347 p.

SILVA, P. C. M.; CHAVES, L. H. G. Avaliação e variabilidade espacial de fósforo, potássio e matéria orgânica em Alissolos. Revista Brasileira de Engenharia Agrícola e Ambiental, v. 5, n. 03, p. 431-436, 2001.

SILVA, S. A. et al. Variabilidade espacial do fósforo e das frações granulométricas de um Latossolo Vermelho Amarelo. Revista Ciência Agronômica, v. 41, n. 01, p. 1-8, 2010.

SILVEIRA, P. M.; STONE, L. F. Teores de nutrientes e matéria orgânica afetados pela rotação de culturas e sistema de preparo do solo. Revista Brasileira de Ciência do Solo, v. 25, p. 387-394, 2001.

SOUZA, Z. M.; ALVES, M. C. Propriedades químicas de um Latossolo Vermelho distroférrico de cerrado sob diferentes usos e manejos. Revista Brasileira de Ciência do Solo, v. 27, n. 01, p. 133-139, 2003.

SOUZA, Z. M. et al. Variabilidade espacial da textura de um Latossolo Vermelho Amarelo eutroférrico sob cultivo de cana-deaçúcar. Engenharia Agrícola, v. 24, n. 02. p. 309-319, 2004a.

SOUZA, Z. M. et al. Variabilidade espacial do pH, Ca, Mg e V\% do solo em diferentes formas do relevo sob cultivo de cana-deaçúcar. Ciência Rural, v. 34, n. 06, p. 1763-1771, $2004 b$.

ZANÃO JÚNIOR, L. A.; LANA, R. M. Q.; GUIMARÃES, E. C. Variabilidade espacial do $\mathrm{pH}$, teores de matéria orgânica e micronutrientes em profundidade em um Latossolo Vermelho sob semeadura direta. Ciência Rural, v. 37, n. 04, p. 10001007, 2007.

ZIMBACK, C. R. L. Análise espacial de atributos químicos de solos para fins de mapeamento da fertilidade do solo. 2001. 114 f. Tese (Livre-Docência) - Faculdade de Ciências Agronômicas, Universidade Estadual Paulista, Botucatu, 2001

WARRICK, A. W.; NIELSEN, D. R. Spatial variability of soil physical properties in the field. In: HILLEL, D. (Ed.). Applications of soil physics. New York: Academic, 1980. cap. 2, p. 319-344. 